\title{
Thermal dechlorination of PCB-209 over Ca species-doped $\mathrm{Fe}_{2} \mathrm{O}_{3}$
}

\author{
Guijin Su ${ }^{a, *}$, Linyan Huang ${ }^{a}$, Ruifang Shi ${ }^{\text {a,b }}$, Yexuan Liu ${ }^{a}$, Huijie Lu ${ }^{a}$, Yuyang Zhao ${ }^{a}$, \\ Fan Yang ${ }^{\mathrm{a}}$, Lirong Gao ${ }^{\mathrm{a}, * *}$, Minghui Zheng ${ }^{\mathrm{a}}$ \\ a State Key Laboratory of Environmental Chemistry and Ecotoxicology, Research Center for Eco-environmental Sciences, Chinese Academy of Sciences, P.O. \\ Box 2871, Beijing 100085, China \\ ${ }^{\mathrm{b}}$ Ausenco LTD, Beijing 100027, China
}

\section{H I G H L I G H T S}

- $1 \%$ mol Ca species enhanced the activity of $\mathrm{Fe}_{2} \mathrm{O}_{3}$ in the degradation of DecaCB.

- Dominant Nona-MonoCB isomers were determined during hydrodechlorination reaction.

- Thermodynamic and/or steric effects drive conversion.

- Steric effect prevented the hydrodechlorination at ortho-positions.

\section{A R T I C L E I N F O}

\section{Article history:}

Received 12 February 2015

Received in revised form 3 August 2015

Accepted 3 August 2015

Available online 5 September 2015

Handling editor: H. Fiedler

\section{Keywords:}

Ca species-doped $\mathrm{Fe}_{2} \mathrm{O}_{3}$

Polychlorinated biphenyls

Hydrodechlorination

Steric effect

\begin{abstract}
A B S T R A C T
Degradation reaction of decachlorobiphenyl (PCB-209) was investigated over the synthesized Ca speciesdoped $\mathrm{Fe}_{2} \mathrm{O}_{3}$ at $300{ }^{\circ} \mathrm{C}$. The $1 \% \mathrm{Ca}-\mathrm{Fe}_{2} \mathrm{O}_{3}$ exhibited the highest activity among the four catalysts prepared with the pseudo-first order reaction at $k_{o b s}=0.103 \mathrm{~min}^{-1}$. PCB-207, PCB-197, PCB-176, PCB-184, PCB-150, PCB-136, PCB-148, РCB-104, РCB-96, PCB-54, РCB-19, РCB-4 and PCB-1 were identified as the dominant isomers in their respective nonachlorobiphenyl (NonaCB) to monochlorobiphenyl (MonoCB) homologue groups. Analysis of the hydrodechlorination products indicated that dechlorination was much more favored on meta- and para-than on ortho-positions. The formation of significantly predominant NonaCB and octachlorobiphenyl (OctaCB) isomers was attributed to lower energy principles and to the $90^{\circ}$ dihedral angles of two aromatic rings which prevented the hydrodechlorination at ortho-positions. When the number of chlorine atoms is not more than 7 , the steric effect supports the formation of predominant PCB isomers having chlorines at four ortho-positions. During the dechlorination of tetrachlorobiphenyl (TetraCB) formed to generate monochlorobiphenyl (MonoCB) isomers, the chlorine atoms fully substituted at the ortho-positions have to be successively removed, with the first two dechlorinations preferentially occurring at the two different benzene rings. This is dissimilar to that of octachloronaphthalene (PCN-75) in which the hydrodechlorination reaction happened preferentially at ortho-position due to the existence of steric effects. The opposite roles of the steric effect in ortho-position between PCB-209 and PCN-75 might be due to the difference of the $\pi$-conjugated plane caused by the dihedral angle of $90^{\circ}$ and $0^{\circ}$ of the two aromatic rings.
\end{abstract}

(c) 2015 Elsevier Ltd. All rights reserved.

\section{Introduction}

Polychlorinated biphenyls (PCBs) are ubiquitous environmental pollutants that have 209 possible compounds, featuring 1-10 chlorine atoms. PCBs were proposed for inclusion into Annex A and $\mathrm{C}$ of the Stockholm Convention (SC) on POPs (The 12 initial POPs under the Stockholm Convention), which are extremely harmful to human health and the environment because of their high toxic-

\footnotetext{
* Corresponding author.

** Corresponding author.

E-mail addresses: gjsu@rcees.ac.cn (G. Su), gaolr@rcees.ac.cn (L. Gao).
}

ity and bioaccumulation through the food web. They have been widely used as dielectric fluids in electrical transformers and capacitors, plasticizers in paints, and dye carriers in carbonless copy paper (Abramowicz, 1990). Although the production of PCBs has been banned since the mid-1970s, large amounts of PCBs have been released into the environment because of their historically widespread use. According to the estimation in 2008, the global quantity of PCBs amounted to 2.9 million tonnes (The PCBs elimination network: the information exchange platform created for the risk reduction of polychlorinated biphenyls). Once released into the environment, those PCBs can be transported and distributed on a global scale by the global fractionation and grasshopper effect (Wania, 2003; Gouin et al., 2004). The reducing of PCBs is 
therefore a matter of public concern in the context of environmental protection.

According to Annex A part II of the Stockholm Convention, Parties to the Convention are obliged to eliminate PCBs wastes from use by 2025 and bring these under environmentally sound waste management by 2028 (PCBs Elimination Network). Hightemperature incineration is currently the principal method of PCBs destruction (Lee and Huffman, 1989). However, there are considerable problems, including the high cost and the possible generation of more toxic polychlorinated dibenzodioxins/polychlorinated dibenzofurans during incineration (Addink and Olie, 1995). Catalytic degradation at lower temperature involving metal oxides as a safe alternative technology is thought as the most promising method, due to its relatively low costs, high levels of activity (Subbanna et al., 1988; Tanaka et al., 2005; Huang et al., 2013). Numerous metal oxides exhibited high activity in the decomposition of PCBs, including $\mathrm{Cr}_{2} \mathrm{O}_{3}, \mathrm{CO}_{3} \mathrm{O}_{4}, \mathrm{CuO}, \mathrm{Al}_{2} \mathrm{O}_{3}, \mathrm{La}_{2} \mathrm{O}_{3}$ (Subbanna et al., 1988; Tanaka et al., 2005). Subbanna et al. (1988) reported that the activity of $10 \% \mathrm{CuO}$ supported on $\alpha-\mathrm{Al}_{2} \mathrm{O}_{3}$ in the decomposition of Aroclor 1254 was better than those of supported $4 \%$ $\mathrm{Cr}_{2} \mathrm{O}_{3}$ and $6 \% \mathrm{Co}_{3} \mathrm{O}_{4}$, with a destruction efficiency of $97.3 \%$. However, most of these metal oxides are expensive or difficult to obtain, and their applications in catalytic degradation of PCBs are limited.

$\mathrm{CaO}$ and $\mathrm{Fe}_{2} \mathrm{O}_{3}$ as facile resource on the earth, their activities on the destruction of chlorinated organic compounds have been examined (Hooker and Klabunde, 1994; Li et al., 1994; Koper et al., 1997; Jia et al., 2011). Li et al. (1994) reported that the presence of $\mathrm{CaO}$ allowed the destruction of chlorinated benzenes at lower temperatures than those needed in simple pyrolysis or combustion processes. Jia et al. (2011) synthesized flower-like $\alpha-\mathrm{Fe}_{2} \mathrm{O}_{3}$ with relatively high activity in the destruction of hexachlorobenzene $(\mathrm{HCBz})$. Further studies have shown that the reaction efficiencies can be significantly improved by the presence of $\mathrm{Ca}$ and Fe composite oxides because of their synergic effects (Jiang et al., 1998; Decker et al., 2002; Ma et al., 2005b). Decker et al. (2002) found that the presence of a small amount of $\mathrm{Fe}_{2} \mathrm{O}_{3}$ on $\mathrm{CaO}$ improved the reaction efficiency. Ma et al. (2005a, 2005b) reported that both physical mixture of $\alpha-\mathrm{Fe}_{2} \mathrm{O}_{3}$ and $\mathrm{CaO}$ and $\mathrm{Ca}-\mathrm{Fe}$ composite oxides prepared by coprecipitation had synergic effects on $\mathrm{HCBz}$ decomposition. However, to the best of our knowledge, no studies on the activities of $\mathrm{Ca}-\mathrm{Fe}$ composite oxides with different $\mathrm{Ca}$ doping amount in the decomposition of PCBs have been reported. Furthermore, the driving force during hydrodechlorination of PCBs over metal oxides was rarely discussed.

In the present work, Ca species-doped $\mathrm{Fe}_{2} \mathrm{O}_{3}$ samples with different $\mathrm{Ca} / \mathrm{Fe}$ molar ratios were prepared and characterized. The activities of the materials were investigated based on their degradation efficiencies toward PCB-209, with fully chlorine-substituted compound as a model PCB. The kinetics of the degradation of PCB-209 over $\mathrm{Fe}_{2} \mathrm{O}_{3}$ doped with $1 \mathrm{~mol} \% \mathrm{Ca}$ was studied. Series of hydrodechlorination products were identified using gas chromatograph-mass spectrometry. The driving force of PCB hydrodechlorination reaction during different steps was discussed on the basis of the isomer distribution pattern in combination with thermodynamic data and steric effect. The results generated in the present study were compared with those obtained from PCN-75 degradation reported in our previous work under similar reaction conditions (Su et al., 2014).

\section{Material and methods}

\subsection{Materials}

All chemicals, including $\mathrm{Fe}\left(\mathrm{NO}_{3}\right)_{3} \cdot 9 \mathrm{H}_{2} \mathrm{O}, \mathrm{Ca}\left(\mathrm{NO}_{3}\right)_{2} \cdot 4 \mathrm{H}_{2} \mathrm{O}$, urea, and polyethylene glycol (PEG) 10000 were analytic grade and pur- chased from Beijing Chemical Co. (Beijing, China), and used without further purification. PCB-209 was purchased from Dr. Ehrenstorfer $\mathrm{GmbH}$, Germany. Hexane of pesticide grade was purchased from Dikma Technologies Inc.

\subsection{Preparation of $\alpha-\mathrm{Fe}_{2} \mathrm{O}_{3}$ and $\mathrm{Ca}$ species-doped $\mathrm{Fe}_{2} \mathrm{O}_{3}$ with different $\mathrm{Ca} / \mathrm{Fe}$ molar ratios}

Iron oxide was synthesized by an ethylene glycol-mediated reaction using a previously reported method (Zhong et al., 2006; Jia et al., 2011). In a typical procedure, $1.9 \mathrm{~g} \mathrm{Fe}\left(\mathrm{NO}_{3}\right)_{3} \cdot 9 \mathrm{H}_{2} \mathrm{O}, 2.7 \mathrm{~g}$ urea, and $1.5 \mathrm{~g}$ PEG 10000 were added to $180 \mathrm{~mL}$ ethylene glycol. The mixture was magnetically stirred and refluxed at $230^{\circ} \mathrm{C}$ for $30 \mathrm{~min}$, and then cooled to room temperature. The precipitated precursor was centrifuged and washed three times with ethanol, then dried in an oven at $105{ }^{\circ} \mathrm{C}$ overnight. $\alpha-\mathrm{Fe}_{2} \mathrm{O}_{3}$ was obtained by calcination of the above precursor at $350{ }^{\circ} \mathrm{C}$ in tube furnace under air atmosphere.

Ca species-doped $\mathrm{Fe}_{2} \mathrm{O}_{3}$ with different $\mathrm{Ca} / \mathrm{Fe}$ molar ratios was prepared by impregnating the above iron oxide precursor with $\mathrm{Ca}\left(\mathrm{NO}_{3}\right)_{2} \cdot 4 \mathrm{H}_{2} \mathrm{O}$. A known amount of $\mathrm{Ca}\left(\mathrm{NO}_{3}\right)_{2} \cdot 4 \mathrm{H}_{2} \mathrm{O}$ was dissolved in ethanol, then the iron oxide precursor was added with $\mathrm{Ca} / \mathrm{Fe}$ molar ratios of 1:99, 5:95, and 50:50. The mixture was mixed with ultrasonic wave, and then dried in an oven. The dried precursor was calcined at $350{ }^{\circ} \mathrm{C}$ for $3 \mathrm{~h}$ in air, giving Ca species-doped $\mathrm{Fe}_{2} \mathrm{O}_{3}$. The $\mathrm{Ca}$ species-doped $\mathrm{Fe}_{2} \mathrm{O}_{3}$ samples with $\mathrm{Ca} / \mathrm{Fe}$ molar ratios of $1: 99,5: 95$, and 50:50 were denoted by $1 \% \mathrm{Ca}-\mathrm{Fe}_{2} \mathrm{O}_{3}, 5 \% \mathrm{Ca}-$ $\mathrm{Fe}_{2} \mathrm{O}_{3}$, and $50 \% \mathrm{Ca}-\mathrm{Fe}_{2} \mathrm{O}_{3}$, respectively.

\subsection{Characterization of $\mathrm{Ca}$ species-doped $\mathrm{Fe}_{2} \mathrm{O}_{3}$}

The materials were characterized using scanning electron microscopy (Hitachi S-3000N), thermogravimetric analysis and differential scanning calorimetry (TGA-DSC, microcomputer differential thermal balance, Hengjiu, Beijing, China). TGA/DSC experiments were performed between ambient temperature and $800^{\circ} \mathrm{C}$, with a heating rate of $20{ }^{\circ} \mathrm{C} \mathrm{min}-1$ in an air flow. The surface area and pore characterization of the materials were obtained from $\mathrm{N}_{2}$ adsorption/desorption analysis at $-196{ }^{\circ} \mathrm{C}$ using a Quantachrome Quadrasorb SI-MP. XRD patterns of the samples were obtained with a Rigaku D/max 2500 diffractometer using $\mathrm{Cu} \mathrm{K} \alpha$ radiation $(\lambda=0.154056 \mathrm{~nm}, 40 \mathrm{kV}, 200 \mathrm{~mA})$.

\subsection{Activity measurements}

The reaction activities of the prepared metal oxides were tested in sealed glass ampoules. Prior to the reaction, $0.4 \mathrm{~mL}$ of a hexane solution of PCB-209 (0.4 mg PCB-209) were injected into an ampoule, evaporated to dryness at room temperature, and then mixed with $50 \mathrm{mg} \alpha-\mathrm{Fe}_{2} \mathrm{O}_{3}$ or Ca species-doped $\mathrm{Fe}_{2} \mathrm{O}_{3}$. The ampoule was sealed in the atmosphere and heated at $300{ }^{\circ} \mathrm{C}$ for $10-60 \mathrm{~min}$. The sealed ampoule was then cooled to room temperature, crushed and extracted with hexane under ultrasonic condition for product analysis and reaction activity evaluation. All experiments were performed in triplicate to ensure the repeatability of the results, and the average values were used. The relative standard deviations of all experimental data were lower than $8 \%$.

\subsection{Product analysis}

The samples were extracted with hexane and dehydrated using anhydrous sodium sulfate. The extract was then analyzed for unreacted PCB-209 and newly formed PCBs, using an Agilent 6890 gas chromatograph equipped with a DB-5MS capillary column (30 m $\times 0.25 \mathrm{~mm}$ i.d., $0.25 \mu \mathrm{m}$ film thickness), coupled with an Agilent 5973N mass selective detector. Helium carrier gas 
was used during gas chromatography $(\geq 99.999 \%)$ at a flow rate of $1 \mathrm{~mL} \mathrm{~min}^{-1}$. In each run, a $1.0-\mu \mathrm{L}$ aliquot of the diluted sample was injected in the splitless mode. The injector was set at $280^{\circ} \mathrm{C}$ while the column temperature was initially held at $50{ }^{\circ} \mathrm{C}$ for $5 \mathrm{~min}$, gradually increased to $80{ }^{\circ} \mathrm{C}$ at $3{ }^{\circ} \mathrm{C} \mathrm{min}-1$, then to $180{ }^{\circ} \mathrm{C}$ at 5. ${ }^{\circ} \mathrm{C}$ min $^{-1}$ and finally to $280{ }^{\circ} \mathrm{C}$ at $8{ }^{\circ} \mathrm{C} \mathrm{min}-1$. The qualitative and quantitative determinations of PCBs were conducted according to EPA method 1668B. Qualitative determinations of produced PCBs were based on the $m / z$ data, the retention times of ${ }^{13} \mathrm{C}_{12}$-labeled PCBs standards and the relative retention time intervals between adjacent congeners. Quantitative determinations were performed in the selected ion monitoring mode, using two most abundant ions of the molecular ion clusters combined with those of the corresponding or adjacent ${ }^{13} \mathrm{C}_{12}$-labeled PCB standards.

\section{Results and discussion}

\subsection{Characterizations of $\mathrm{Ca}$ species-doped $\mathrm{Fe}_{2} \mathrm{O}_{3}$}

The thermal behaviors of the $\mathrm{Ca}$ species-doped $\mathrm{Fe}_{2} \mathrm{O}_{3}$ precursors were studied using TGA/DSC (Fig. 1). The $1 \% \mathrm{Ca}-\mathrm{Fe}_{2} \mathrm{O}_{3}$ and $5 \% \mathrm{Ca}-\mathrm{Fe}_{2} \mathrm{O}_{3}$ samples exhibited two weight loss steps. The first step, up to $200{ }^{\circ} \mathrm{C}$, was caused by removal of physisorbed water, crystal water in $\mathrm{Ca}\left(\mathrm{NO}_{3}\right)_{2}$ hydrates, and residual solvent in the pores (Zhou et al., 2012), and the weight loss was about 3\%. The second step, between 200 and $350{ }^{\circ} \mathrm{C}$, corresponded to the removal of nitrate groups and the decomposition of iron alkoxides (Larcher et al., 2003). In contrast, for the $50 \% \mathrm{Ca}-\mathrm{Fe}_{2} \mathrm{O}_{3}$ sample, there were three weight loss steps. The significant weight loss before $100{ }^{\circ} \mathrm{C}$ was mainly the results of the removal of crystal water in hydrates and physisorbed water, with a weight loss of about $17 \%$. The second step, between 100 and $200{ }^{\circ} \mathrm{C}$, was assigned to the further removal of crystal water and evaporation of residual solvent in the pores, with a weight loss of about $3 \%$. The significant weight loss in the temperature range $200-350{ }^{\circ} \mathrm{C}$ could be attributed to the removal of nitrate groups and the decomposition of iron alkoxides, with a weight loss of about 71\% (Larcher et al., 2003). Since the precursor's weight did not decrease greatly above $350{ }^{\circ} \mathrm{C}$, the $\mathrm{Ca}$ species-doped $\mathrm{Fe}_{2} \mathrm{O}_{3}$ was obtained by precursor calcination at $350{ }^{\circ} \mathrm{C}$ in air. Two distinct regions, corresponding to the weight loss steps in the TGA curves, were observed in the DSC profiles in the temperature range $25-350{ }^{\circ} \mathrm{C}$ (Fig. 1b). The first region, up to $200{ }^{\circ} \mathrm{C}$, was characteristic of an endothermic peak which was only observed in $50 \% \mathrm{Ca}$-doped $\mathrm{Fe}_{2} \mathrm{O}_{3}$ precursor, and confirmed the removal of physisorbed and crystal water from the precursors (Zhou et al., 2012). The second region, ranging from 200 to $350{ }^{\circ} \mathrm{C}$, included prominent exothermic peaks, indicating the formation of Ca species-doped $\mathrm{Fe}_{2} \mathrm{O}_{3}$ (Lu et al., 2008; Zhou et al., 2012). The exothermic peak in $50 \%$ Ca-doped $\mathrm{Fe}_{2} \mathrm{O}_{3}$ precursor was obviously lower than those in the other two samples. Since the $\mathrm{Fe}_{2} \mathrm{O}_{3}$ precursor was confirmed to be iron alkoxide in previous work (Zhong et al., 2006), its decomposition during the thermogravimetry process was exothermic. However, the decomposition of $\mathrm{Ca}\left(\mathrm{NO}_{3}\right)_{2}$ was an endothermic process. The higher percentage of $\mathrm{Ca}\left(\mathrm{NO}_{3}\right)_{2}$ in $50 \% \mathrm{Ca}$-doped $\mathrm{Fe}_{2} \mathrm{O}_{3}$ precursor led to the significant decrease of exothermic peak.

The morphologies of the synthesized Ca species-doped $\mathrm{Fe}_{2} \mathrm{O}_{3}$ as compared to that of $\alpha-\mathrm{Fe}_{2} \mathrm{O}_{3}$ samples are shown in Fig. 2. As previously reported, the synthesized $\alpha-\mathrm{Fe}_{2} \mathrm{O}_{3}$ consisted of many uniform, flower-like structures of diameter 1.0-1.5 $\mu \mathrm{m}$ (Fig. 2a), and the flower-like architecture was built up from many nanopetals (Jia et al., 2011). After little addition of $\mathrm{Ca}\left(\mathrm{NO}_{3}\right)_{2} \cdot 4 \mathrm{H}_{2} \mathrm{O}$ to the $\mathrm{Fe}_{2} \mathrm{O}_{3}$ precursor and calcination at $350{ }^{\circ} \mathrm{C}$, the morphology of the material was not changed obviously (Fig. 2b). The formed Ca-contained compounds dispersed well on the surface of $\mathrm{Fe}_{2} \mathrm{O}_{3}$, due to the impregnation during the preparation process of ultrasonic treatment. It was reported that ultrasound made sample thin and resistant to reunion due to the propagation of ultrasonic wave through liquid media and the collapse of cavitation bubbles (Zhu et al., 2007). When the Ca molar ratio increased to $5 \%$, the material surface turned into vague (Fig. 2c). When the molar ratio of Ca was further increased to $50 \%$, the petals completely disappeared (Fig. 2d), and were replaced by smooth surface. The material on the surface covering the gaps between the petals might be a newly formed Cacontaining composite metal oxide.

As shown in Fig. 3a, the product obtained by calcining the iron oxide precursor at $350{ }^{\circ} \mathrm{C}$ in air was pure $\alpha$ - $\mathrm{Fe}_{2} \mathrm{O}_{3}$ (JCPDS 01089-0599). Besides the dominated $\alpha-\mathrm{Fe}_{2} \mathrm{O}_{3}$ phase, little $\gamma-\mathrm{Fe}_{2} \mathrm{O}_{3}$ (JCPDS 00-025-1402) and $\mathrm{Ca}_{2} \mathrm{Fe}_{2} \mathrm{O}_{5}$ (JCPDS 00-018-0286) (Ma et al., 2005a) was formed in $1 \% \mathrm{Ca}-\mathrm{Fe}_{2} \mathrm{O}_{3}$, as showed in Fig. 3b. When the $\mathrm{Ca} / \mathrm{Fe}$ molar ratio was 5:95, the $\mathrm{Fe}_{2} \mathrm{O}_{3}$ peaks turned broad and the $\gamma-\mathrm{Fe}_{2} \mathrm{O}_{3}$ (maghemite, JCPDS 00-024-0081) was the dominant phase, as showed in Fig. 3c. The reason would be that the decomposition of iron alcoholate was in a hypoxia environment due to the covering of $\mathrm{Ca}\left(\mathrm{NO}_{3}\right)_{2} \cdot 4 \mathrm{H}_{2} \mathrm{O}$ on the surface, resulting in the phase transformation to $\gamma-\mathrm{Fe}_{2} \mathrm{O}_{3}$ (Zhong et al., 2006). When the $\mathrm{Ca} / \mathrm{Fe}$ molar ratio was increased to 50:50, the dominant phase changed to $\mathrm{Ca}_{2} \mathrm{Fe}_{2} \mathrm{O}_{5}$ (JCPDS 00-019-0222), and only a few $\mathrm{Fe}_{2} \mathrm{O}_{3}$ diffraction peaks were detected, as showed in Fig. $3 \mathrm{~d}$.

Table 1 provides a summary of the pore structure data for the $\mathrm{Ca}$ species-doped $\mathrm{Fe}_{2} \mathrm{O}_{3}$ and $\alpha-\mathrm{Fe}_{2} \mathrm{O}_{3}$ sample series. The specific surface area of $\alpha-\mathrm{Fe}_{2} \mathrm{O}_{3}$ was $25 \mathrm{~m}^{2} \mathrm{~g}^{-1}$. When $1 \% \mathrm{Ca}$ was adopted onto $\mathrm{Fe}_{2} \mathrm{O}_{3}$, the specific surface area increased dramatically to $61 \mathrm{~m}^{2} \mathrm{~g}^{-1}$. The significantly larger BET surface area of the
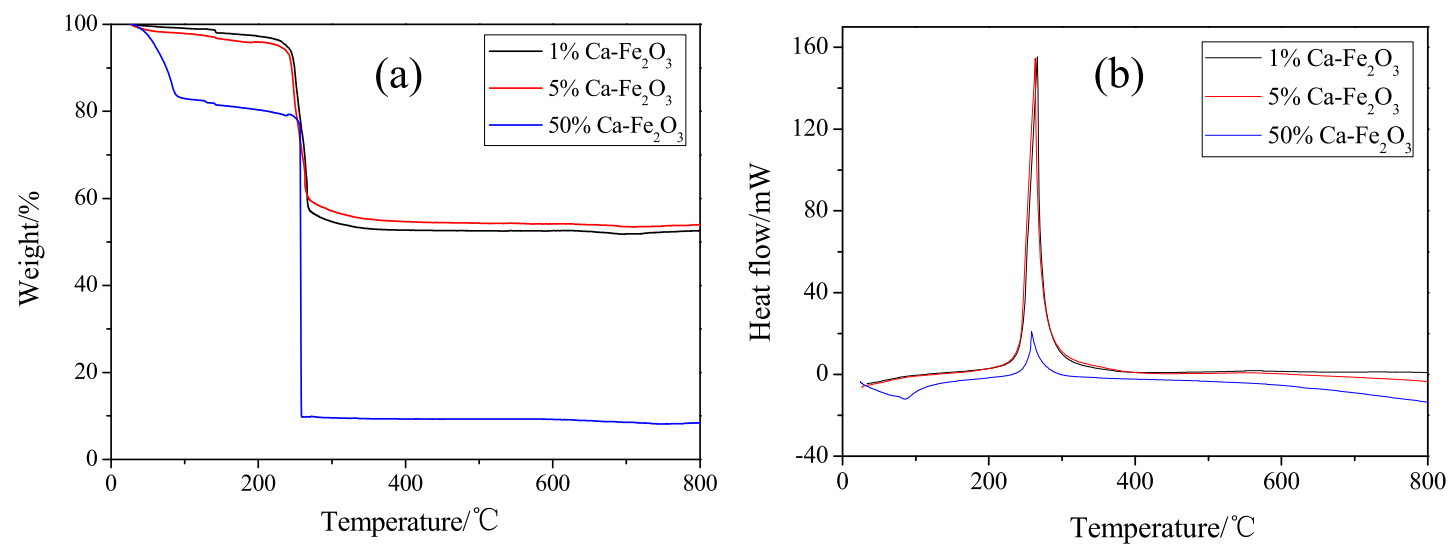

Fig. 1. TGA curves (a) and DSC curves (b) of prepared Ca species-doped $\mathrm{Fe}_{2} \mathrm{O}_{3}$ precursors. 

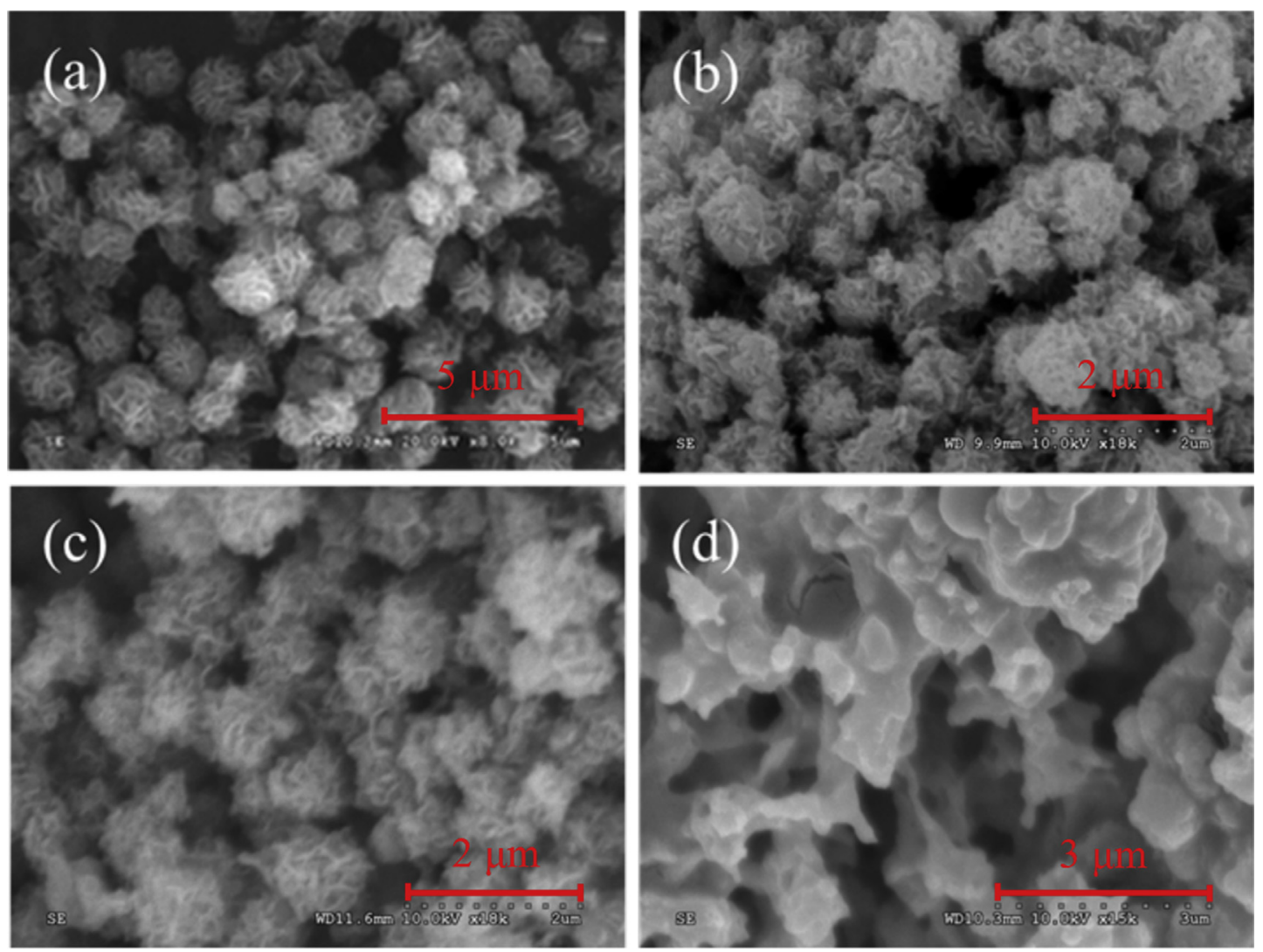

Fig. 2. SEM images of Ca species-doped $\mathrm{Fe}_{2} \mathrm{O}_{3}$ : (a) $\mathrm{Fe}_{2} \mathrm{O}_{3}$; (b) $1 \% \mathrm{Ca}-\mathrm{Fe}_{2} \mathrm{O}_{3}$; (c) $5 \% \mathrm{Ca}-\mathrm{Fe}_{2} \mathrm{O}_{3}$; and (d) $50 \% \mathrm{Ca}-\mathrm{Fe}_{2} \mathrm{O}_{3}$.

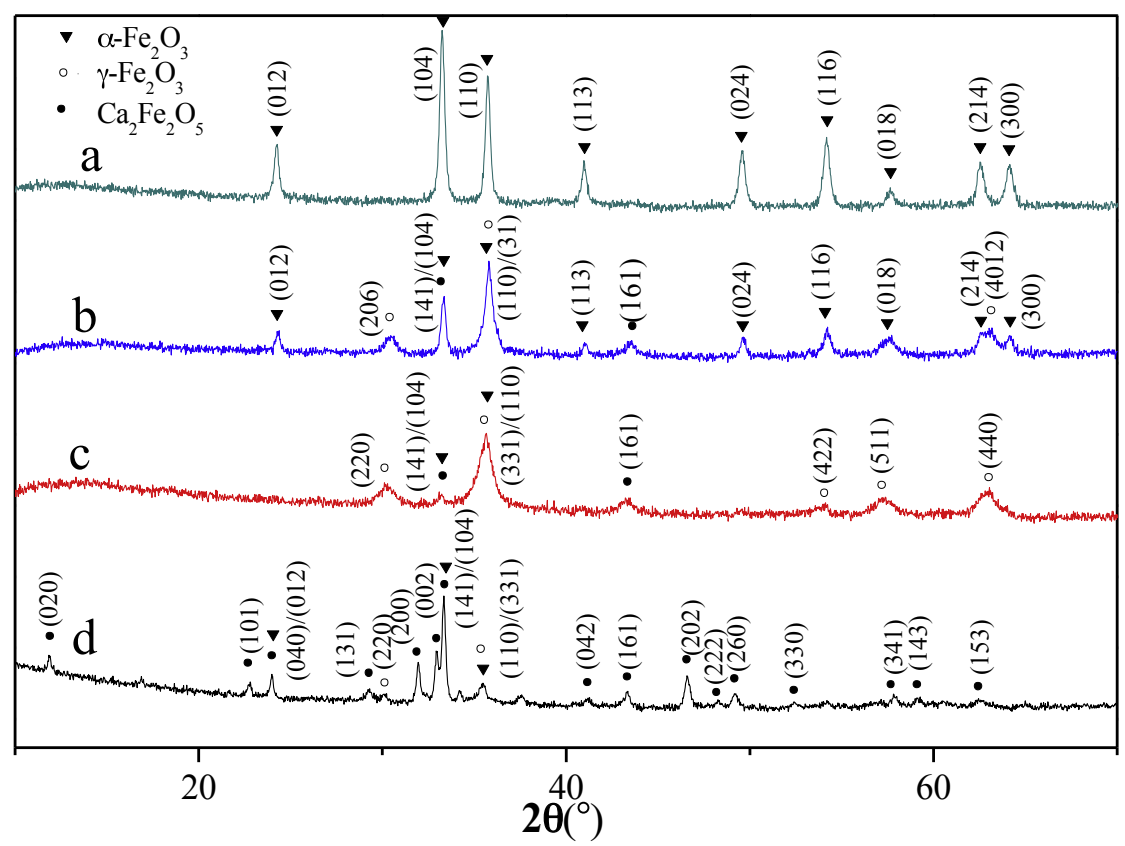

Fig. 3. XRD patterns of prepared materials: (a) $\mathrm{Fe}_{2} \mathrm{O}_{3}$; (b) $1 \% \mathrm{Ca}-\mathrm{Fe}_{2} \mathrm{O}_{3}$; (c) $5 \% \mathrm{Ca}-\mathrm{Fe}_{2} \mathrm{O}_{3}$; and (d) $50 \% \mathrm{Ca}-\mathrm{Fe}_{2} \mathrm{O}_{3}$.

$1 \% \mathrm{Ca}-\mathrm{Fe}_{2} \mathrm{O}_{3}$ compared to $\alpha-\mathrm{Fe}_{2} \mathrm{O}_{3}$ might be attributed to the increase in the pore volume from 0.21 to $0.35 \mathrm{~cm}^{3} \mathrm{~g}^{-1}$. In combination with the XRD results, these results might be related to the formation of new $\mathrm{Ca}_{2} \mathrm{Fe}_{2} \mathrm{O}_{5}$. Similar case was reported during the preparation of $\mathrm{Mg}_{\mathrm{x}} \mathrm{SiO}$ via the impregnation method with $\mathrm{SiO}_{2}$ and an aqueous solution of $\mathrm{MgCl}_{2}$ (Zou et al., 2015). It was found that the BET surface area of $\mathrm{Mg}_{0.1} \mathrm{SiO}$ significantly increased to $254 \mathrm{~m}^{2} \mathrm{~g}^{-1}$, compared to that of $\mathrm{SiO}_{2}$ at $197 \mathrm{~m}^{2} \mathrm{~g}^{-1}$, and this change was related to the formation of $\mathrm{MgSiO}_{3}$. However, in the Ca species-doped $\mathrm{Fe}_{2} \mathrm{O}_{3}$ sample series, the specific surface areas and pore volumes both decreased with increasing $\mathrm{Ca} / \mathrm{Fe}$ molar ratios, being for $5 \% \mathrm{Ca}-\mathrm{Fe}_{2} \mathrm{O}_{3}$ at $47 \mathrm{~m}^{2} \mathrm{~g}^{-1}$ and $0.25 \mathrm{~cm}^{3} \mathrm{~g}^{-1}$, and 
Table 1

Pore structure parameters of different materials.

\begin{tabular}{|c|c|c|c|}
\hline & Surface area $\left(\mathrm{m}^{2} \mathrm{~g}^{-1}\right)$ & Average pore diameter (nm) & Pore volume ( $\left.\mathrm{cc} \mathrm{g}^{-1}\right)$ \\
\hline $\mathrm{Fe}_{2} \mathrm{O}_{3}$ & 25 & 31.5 & 0.21 \\
\hline $1 \% \mathrm{Ca}-\mathrm{Fe}_{2} \mathrm{O}_{3}$ & 61 & 23.34 & 0.35 \\
\hline $5 \% \mathrm{Ca}-\mathrm{Fe}_{2} \mathrm{O}_{3}$ & 47 & 21.44 & 0.25 \\
\hline $50 \% \mathrm{Ca}-\mathrm{Fe}_{2} \mathrm{O}_{3}$ & 11 & 19.96 & 0.06 \\
\hline
\end{tabular}

$50 \% \mathrm{Ca}-\mathrm{Fe}_{2} \mathrm{O}_{3}$ at $11 \mathrm{~m}^{2} \mathrm{~g}^{-1}$ and $0.06 \mathrm{~cm}^{3} \mathrm{~g}^{-1}$, respectively. It is possible that additional increases in the amount of $\mathrm{Ca}_{2} \mathrm{Fe}_{2} \mathrm{O}_{5}$ lead to greater coverage of the surface of the materials, blocking the pores between the $\mathrm{Fe}_{2} \mathrm{O}_{3}$ nanopetals, as can be seen in SEM images (Zou et al., 2015).

\subsection{Activity test}

\subsubsection{PCB-209 degradation efficiencies over Ca species-doped $\mathrm{Fe}_{2} \mathrm{O}_{3}$} and $\alpha-\mathrm{Fe}_{2} \mathrm{O}_{3}$

The PCB-209 degradation efficiencies (DE) over Ca speciesdoped $\mathrm{Fe}_{2} \mathrm{O}_{3}$ and $\alpha-\mathrm{Fe}_{2} \mathrm{O}_{3}$ were calculated using following equation:

$\mathrm{DE}=\left(1-R_{P C B-209} / I_{P C B-209}\right) \times 100 \%$

where $I_{P C B-209}$ is the initial number of moles of PCB-209, and $R_{P C B-209}$ is the number of moles of the remained PCB-209 following heating for a given time period. The activities of the materials were evaluated at $300{ }^{\circ} \mathrm{C}$ for $30 \mathrm{~min}$ in sealed ampoules, and the results are shown in Fig. 4a. The degradation efficiency of PCB209 over pure $\alpha-\mathrm{Fe}_{2} \mathrm{O}_{3}$ was $88 \%$. When $1 \%$ of Ca was introduced into $\alpha-\mathrm{Fe}_{2} \mathrm{O}_{3}$, the PCB-209 degradation efficiency increased significantly to $97 \%$. The material's reactivity was primarily related to the number of available surface active sites, and this in turn depended on factors such as the material's surface area, pore volume, and phase composition. The increased surface area would increase the number of active sites, resulting in an increase in the degradation activity (Fan et al., 2011; Huang et al., 2013). Ma et al. (2005a) reported that the formation of $\mathrm{Ca}_{2} \mathrm{Fe}_{2} \mathrm{O}_{5}$ in $\mathrm{Ca}-\mathrm{Fe}$ composite oxide promoted the dechlorination of $\mathrm{HCB}$, whose reaction activity was obviously higher than pure $\mathrm{Fe}_{2} \mathrm{O}_{3}$ and $\mathrm{CaO} . \alpha-\mathrm{Fe}_{2} \mathrm{O}_{3}$ phase in $1 \% \mathrm{Ca}-\mathrm{Fe}_{2} \mathrm{O}_{3}$ catalyst acting as catalyst supporter had dispersive, supporting, and promotion effects to active component $\mathrm{Ca}_{2} \mathrm{Fe}_{2} \mathrm{O}_{5}$ phase (Chen et al., 2006; Wang et al., 2014). $\alpha-\mathrm{Fe}_{2} \mathrm{O}_{3}$ also promoted the catalytic activity of $\mathrm{Ca}_{2} \mathrm{Fe}_{2} \mathrm{O}_{5}$, owing to the interaction between supporter and active component (Tauster et al., 1981). The interaction could enhance the mobility of oxygen species in catalyst (Lin et al., 2012). However, when the molar ratio of Ca increased to $5 \%$, the activity of the material decreased significantly, and even lower than that over pure $\alpha-\mathrm{Fe}_{2} \mathrm{O}_{3}$ which had lower surface area. The reason would be that, on the one hand, the surface of $5 \% \mathrm{Ca}-\mathrm{Fe}_{2} \mathrm{O}_{3}$ was covered by small amount of formed $\mathrm{Ca}_{2} \mathrm{Fe}_{2} \mathrm{O}_{5}$, which blocked the pores and decreased the surface area according to the SEM image as compared to $1 \% \mathrm{Ca}-\mathrm{Fe}_{2} \mathrm{O}_{3}$. On the other hand, the major phase of $5 \% \mathrm{Ca}-\mathrm{Fe}_{2} \mathrm{O}_{3}$ turned to $\gamma-\mathrm{Fe}_{2} \mathrm{O}_{3}$ from $\alpha-\mathrm{Fe}_{2} \mathrm{O}_{3}$. It was reported that the activity of $\gamma-\mathrm{Fe}_{2} \mathrm{O}_{3}$ was obviously lower than that of $\alpha-\mathrm{Fe}_{2} \mathrm{O}_{3}$ (Zhong et al., 2006; Peng et al., 2007). When the molar ratio of Ca further increased to $50 \%$, the activity of the material decreased significantly, and the PCB-209 degradation efficiency was only $5 \%$. This would be due to the very low surface area of $50 \% \mathrm{Ca}-\mathrm{Fe}_{2} \mathrm{O}_{3}$ which could not provide sufficient adsorption and active sites. The above analysis showed that the order of the activities of the prepared materials in PCB-209 degradation was $1 \% \mathrm{Ca}-$ $\mathrm{Fe}_{2} \mathrm{O}_{3}>\alpha-\mathrm{Fe}_{2} \mathrm{O}_{3}>5 \% \mathrm{Ca}-\mathrm{Fe}_{2} \mathrm{O}_{3}>50 \% \mathrm{Ca}-\mathrm{Fe}_{2} \mathrm{O}_{3}$, which indicated that the proper ratio of active compound to supporter of catalyst
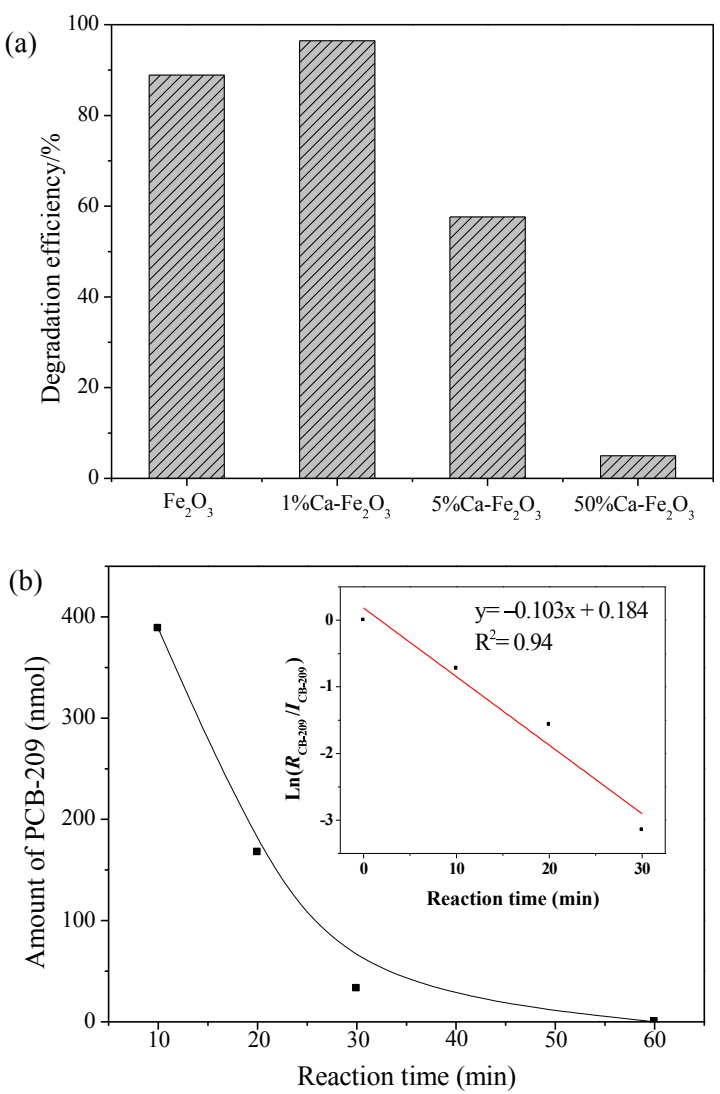

Fig. 4. (a) PCB-209 degradation efficiencies over $\mathrm{Fe}_{2} \mathrm{O}_{3}$ and $\mathrm{Ca}$ species-doped $\mathrm{Fe}_{2} \mathrm{O}_{3}$ at $300{ }^{\circ} \mathrm{C}$ for $30 \mathrm{~min}$; (b) Residual PCB-209 content as a function of reaction time (Inset shows the pseudo-first-order kinetic plot of the reaction).

was an important factor to its activity. It also confirmed that the material activity was affected by both the phase composition and the surface area caused by "Ca-doping effect" (Ma et al., 2014).

As discussed above, the $1 \% \mathrm{Ca}-\mathrm{Fe}_{2} \mathrm{O}_{3}$ material showed the highest activity, so the reaction kinetics was studied by evaluating the time-dependent degradation behavior of PCB-209 (802 nmol) over $1 \% \mathrm{Ca}-\mathrm{Fe}_{2} \mathrm{O}_{3}(50 \mathrm{mg})$ at $300{ }^{\circ} \mathrm{C}$. As shown in Fig. 4b, PCB-209 rapidly decomposed from 802 to $32.8 \mathrm{nmol}$ in $30 \mathrm{~min}$, and further decreased to be under the detection limit in $60 \mathrm{~min}$. This result suggested that flower-like $1 \% \mathrm{Ca}-\mathrm{Fe}_{2} \mathrm{O}_{3}$ was an effective catalyst for the degradation of PCB-209. A linear $\ln \left(R_{P C B-209} / I_{P C B}-209\right)$ vs time plot was obtained that corresponded to pseudo-first-order reaction kinetics, shown in the inset figure of Fig. $4 \mathrm{~b}$. The initial rate of CB-209 decomposition could be described by the pseudo-firstorder kinetic law with respect to PCB-209 concentration, as shown in Eq. (2):

$\ln \left(R_{\mathrm{CB}-209} / I_{\mathrm{CB}-209}\right)=-k_{\text {obs }} t+b$

where $k_{\mathrm{obs}}$ is the pseudo-first-order initial rate constant $\left(\mathrm{min}^{-1}\right)$, as calculated from the experimental data. The pseudo-first-order 
rate constant for the degradation of PCB-209 over $1 \% \mathrm{Ca}-\mathrm{Fe}_{2} \mathrm{O}_{3}$ was $0.103 \mathrm{~min}^{-1}\left(R^{2}=0.94\right)$, which was comparable with that of PCN75 degradation over the prepared $\mathrm{Fe}_{3} \mathrm{O}_{4}$, with pseudo-first-order rate constant of $0.10 \mathrm{~min}^{-1}\left(R^{2}=0.89\right.$ ) (Su et al., 2014). The existence of strong $\pi$-conjugated effects both in PCB-209 and PCN-75 resulted in their similar reaction rate constants.

\subsubsection{Analysis of hydrodechlorination products as compared to that of PCN-75}

For studying the mechanism of PCB-209 degradation over the prepared $1 \% \mathrm{Ca}-\mathrm{Fe}_{2} \mathrm{O}_{3}$ composite oxide, series of hydrodechlorination products were identified.

The content of products was calculated using following equation:

$$
\text { Content }(\%)=\left(N_{P C B S} / I_{P C B-209}\right) \times 100 \%
$$

where $N_{\mathrm{PCBs}}$ is the number of moles of the newly formed PCBs following heating for a given time period, and $I_{\mathrm{CB}-209}$ is the initial number of moles of PCB-209. As observed in Fig. 5, products were identified that included (a) NonaCBs, (b) OctaCBs, (c) heptachlorobiphenyls (HeptaCBs), (d) hexachlorobiphenyls (HexaCBs), (e) pentachlorobiphenyls (PentaCBs), (f) TetraCBs, (g) trichlorobiphenyls (TriCBs), (h) dichlorobiphenyls (DiCBs), and (i) MonoCBs. With increasing reaction time, the amount of all newly formed lower chlorinated biphenyls increased at the early stages of the reaction before a decrease was noted. The detection of newly formed lower chlorinated biphenyls homologues and their time-dependent distribution pattern indicated the occurrence of successive reductive hydrodechlorination reactions during the degradation of PCB-209 over the prepared $1 \% \mathrm{Ca}-\mathrm{Fe}_{2} \mathrm{O}_{3}$. Similar successive reductive hydrodechlorination of PCB-209 over as-prepared $\mathrm{Fe}_{3} \mathrm{O}_{4}$ was also observed with identification of dechlorinated products from NonaCBs to DiCBs (Huang et al., 2013). Furthermore, it is noted that the sum of the residue PCB-209 and the new formed PCBs took $97.6 \%$, $42.6 \%, 12.3 \%$ and $1.55 \%$ of the origin PCB-209 at $10,20,30$, and 60 min, respectively. The sum of all PCBs was not balanced with the original amount of PCB-209, suggesting other products must have been generated. The other products would most probably be the oxidative products due to the high oxidation activity of metal oxides. The simultaneous existence of hydrodechlorination and oxidation reaction have been often determined during the degradation of chlorinated aromatics over metal oxides. The oxidation products, such as phenolate, acetate, and carbon oxide species, have been detected besides lower hydrochlorinated products (Lin et al., 2011; Ma et al., 2007; Schoonenboom et al., 1995; Weber et al., 2002).

Fig. 5 also showed that the lower chlorinated homologues displayed nonuniform distribution profiles of the PCB isomers. In regard to the three isomers of NonaCBs, as shown in Fig. 5a, the content of PCB-207 was markedly higher than that of PCB-208, while none PCB-206 was observed under the present condition. The content of PCB-207 corresponded to $78.4 \%$ of the total amount of NonaCB isomers at a reaction time of $30 \mathrm{~min}$. The amount of intermediate product was determined by both its formation and further degradation rates. The experimental data demonstrated that the stabilities of chlorine atoms substituted on the PCBs were in the order of ortho $>>$ para > meta (Wang et al., 2005; Huang et al., 2013). The reason was that the chlorines on ortho-position had a major influence on the torsional angles and rotational barriers of PCBs, while the effect of adjacent meta chlorine atoms was much smaller (Dorofeeva et al., 2004). Therefore, PCB-209 would proceed to dechlorination on the meta-position preferentially to form PCB-207. Zhai et al. (2005) previously reported the thermodynamic function data for 209 PCB isomers by fully optimized calculation at the B3LYP/6-31G* level, including the total en- ergy (TE), the standard formation energy $\left(\Delta H_{f}^{0}\right)$, and the formation free energy ( $\Delta G_{f}^{573.15}$ ). It was found that these thermodynamic parameters were heavily dependent on the number and position of the chlorine atoms. Among the three NonaCB isomers, the calculated $\Delta G_{f}^{573.15}$ of $\mathrm{PCB}-207$ with $367.28 \mathrm{~kJ} \mathrm{~mol}^{-1}$ was lower than that of PCB-208 and PCB-206 with 367.88 and $371.19 \mathrm{~kJ} \mathrm{~mol}^{-1}$, respectively. In addition, the calculated $\Delta_{f} G_{298}^{0}$ value of PCB-207 with $-22.6 \mathrm{~kJ} \mathrm{~mol}^{-1}$ was also lower than that of PCB-208 and PCB206 with -19.2 and $-15.3 \mathrm{~kJ} \mathrm{~mol}^{-1}$ (Dorofeeva et al., 2004). The lower $\Delta G_{f}^{573.15}$ and $\Delta_{f} G_{298}^{0}$ values indicated PCB-207 was more thermally stable than the other two isomers. Therefore, higher formation rate and lower degradation rate of produced PCB-207 led to its largest amount among the three NonaCB isomers. However, as compared to the degradation of $\mathrm{PCN}-75$ over $\mathrm{Fe}_{3} \mathrm{O}_{4}$, the hydrodechlorination proceeded primarily at the ortho-position to mainly produce PCN-73 (Su et al., 2014).

The produced NonaCB could be further hydrodechlorinated to OctaCBs. As shown in Fig. 5b, PCB-197 was the major isomer and amounted to $46.4 \%$ of the total content of OctaCB isomers at 30 min. It was reported that PCBs with chlorines reasonably distributed at two aromatic rings and their substitution position relatively far were more stable (Zhai et al., 2005). Therefore, PCB197 with symmetrical substituted chlorines was more stable than other OctaCB isomers. Furthermore, the TE, $\Delta H_{f}^{0}$, and $\Delta G_{f}^{573.15}$ values of $-4140.0277,80.31$, and $348.57 \mathrm{~kJ} \mathrm{~mol}^{-1}$, respectively, were lower than those of other detected OctaCB isomers, except that of PCB-201 and PCB-202 which was closed to PCB-197 (Zhai et al., 2005). As compared to the degradation of PCN-75 over $\mathrm{Fe}_{3} \mathrm{O}_{4}$, the hydrodechlorination at the second step also happened preferentially at the ortho-position but at the other side to mainly form PCN-66/67 (Su et al., 2014).

As shown in Fig. $5 \mathrm{c}-\mathrm{e}$, the predominant isomers of the detected HeptaCB, HexaCB, and PentaCB were PCB-176, PCB-184, PCB-150, PCB-136, PCB-148, PCB-104 and PCB-96 at reaction time of $30 \mathrm{~min}$, respectively. On the basis of the thermodynamic data reported by Zhai et al. (2005), the TE, $\Delta H_{f}^{0}$ and $\Delta G_{f}^{573.15}$ of the above main isomers were not the lowest among those obtained for the HeptaCB, HexaCB, and PentaCB isomers. The reason would be that other effects rather than thermodynamic properties were the main driving force of further hydrodechlorination. It was noticed that all the dominant isomers of detected HeptaCBs, HexaCBs, and PentaCBs were fully substituted with chlorines at ortho-position, and the further hydrodchlorination from OctaCBs to PentaCBs preferentially happened at meta- or para-positions. As compared to the degradation of PCN-75 over $\mathrm{Fe}_{3} \mathrm{O}_{4}$, the main hydrodechlorination pathway of PCN-75 after the elimination of two chlorines at ortho-position happened at meta-positions. At the onward step, no predominant PCN isomers distinguished among the detected TetraCN and TriCN isomers, due to their similar thermodynamic parameters (Su et al., 2014).

The contents of PCB-54, PCB-19, PCB-4 and PCB-1 (Fig. 5f-i) contributed to $79.0 \%, 83.4 \%, 77.3 \%$ and $72.7 \%$ of the total detected TetraCB, TriCB, DiCB and MonoCB isomers at $30 \mathrm{~min}$. All of PCB-54, PCB-19, PCB-4 and PCB-1 isomers with one to four chlorine atoms substituted at $C$ atoms in positions $2,2^{\prime}, 6$, or 6 '. However, the thermodynamic data of PCB-54, PCB-19, PCB-4 and PCB- 1 isomers were not the lowest among the detected corresponding isomers (Zhai et al., 2005). The reason would be that chlorine at orthoposition was more stable than at other two positions, although the thermodynamic data of those dominant isomers were not the lowest (Zhai et al., 2005). Besides, all main TetraCB to MonoCB isomers featured the substituted chlorines locating at two different benzene rings. Similarly, PCN-75 mainly dechlorinated to PCN-11/8 which featured the substituted chlorines locating at two different 

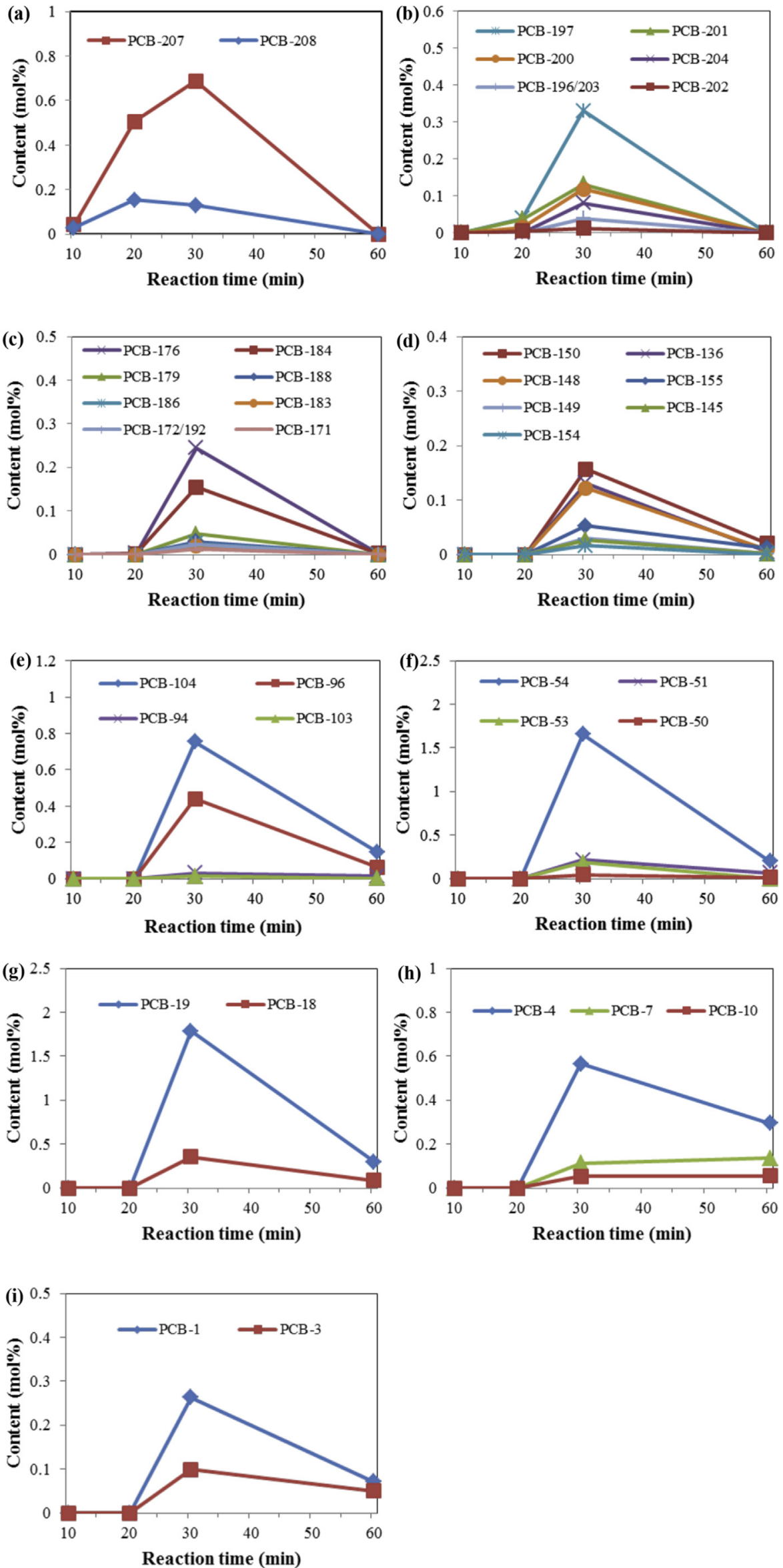

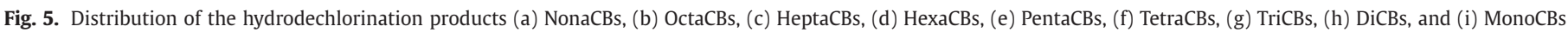
following degradation of PCB-209 over as-prepared $1 \% \mathrm{Ca}-\mathrm{Fe}_{2} \mathrm{O}_{3}$ at $300{ }^{\circ} \mathrm{C}$ as a function of heating time. 
benzene rings (Su et al., 2014). The PCB isomer distribution patterns were quite different with those in transformer oil and global commercial PCB formulations (Takasuga et al., 2006), which might be due to their different formation pathways. PCB-110, PCB-138, PCB-149, and PCB-153 were the main congeners in PCB polluted oil, while the main PCB congeners turned to PCB-3 and PCB-8 in chemically degraded oil (Takasuga et al., 2006).

\subsubsection{The hypothesis of hydrodechlorination mechanism of PCB-209 compared with that of PCN-75}

According to the above analysis of hydrodechlorinated products, higher amounts of PCB-207, PCB-197, PCB-176, PCB-184, PCB150, PCB-136, PCB-148, PCB-104, PCB-96, РCB-54, PCB-19, PCB-4 and $\mathrm{PCB}-1$ were determined in their respective homologues. The hydrodechlorination mechanism of PCB-209 over $1 \% \mathrm{Ca}-\mathrm{Fe}_{2} \mathrm{O}_{3}$ was shown in Fig. 6a. In newly formed dominant NonaCB and OctaCB isomers, four ortho-positions were all substituted with chlorines with their lowest thermodynamic properties. The dechlorination driving force was primarily controlled by thermodynamic stabilities of products and their steric effects which prevent the hydrodechlorination at ortho-position. When the number of substituted chlorines of the newly formed PCBs was less than or equal to 7 , the chlorines of dominated isomers preferentially substituted at ortho-positions. The steric effect keeps the formation of predominant $\mathrm{PCB}$ isomers with chlorines at ortho-positions. During the dechlorination of the formed TetraCB into MonoCB isomers, the chlorine atoms fully substituted in ortho-positions have to be successively removed preferentially at two different benzene rings. The above results meant that chlorines at ortho-positions were the most stable, while those at meta- and para-positions were relatively easer to drop during catalytic degradation of PCB-209 at $300{ }^{\circ} \mathrm{C}$. The dechlorination pattern in our study was similar with that of PCB dechlorination over iron-based spinel at $300{ }^{\circ} \mathrm{C}$ (Huang et al., 2013) and microbial reductive dechlorination of PCBs in soils and aquatic sediments under anaerobic conditions (Wiegel and $\mathrm{Wu}, 2000)$. The dechlorination pattern described above matches $\mathrm{PCB}$ dechlorination Process $\mathrm{N}$, which defined microbiologically mediated dechlorination of PCBs which typically removes meta and/or para chlorines to generate primarily ortho-substituted lower chlorinated biphenyls (Wiegel and Wu, 2000; LaRoe et al., 2014).

The reactivity of chlorines at different substituted position in aromatic compounds was quite related with their geometrical structures. The optimized geometry of the minima states of PCB209 was calculated by DFT at the B3LYP/6-31g(d) theory level, shown in Fig. 6b. The high Coulombic repulsion and steric hindrance elevate the repulsion between the four chlorine atoms at ortho-positions, causing the conformational changes in PCB-209 to be quite distorted, with dihedral angles of two aromatic rings at $90^{\circ}$ (Alonso et al., 2008). The activation energy of the rotation around the aryl-aryl bond is over $56 \mathrm{kcal} \mathrm{mol}^{-1}$ for PCB-209 (Alonso et al., 2008). This result indicates that the existence of a coplanar structure in PCB-209 can be completely discarded. The existence of the $90^{\circ}$ dihedral angles resulted in the $\mathrm{C}-\mathrm{Cl}$ bonds at ortho-position are stable and resistant to be attacked from any directions. Whereas the chlorines in meta- and para-position are relatively easy to be sterically attacked from the top and bottom of two aryl planes. This can also be reflected by the higher bond dissociation energy (BDE) of $\mathrm{C}-\mathrm{Cl}$ bonds at ortho-position at $357.28 \mathrm{~kJ} \mathrm{~mol}^{-1}$ than those of at meta- and para-position at 353.98 and $351.69 \mathrm{~kJ} \mathrm{~mol}^{-1}$, respectively. Therefore, in the main dechlorination pathway, chlorines in meta- and para-position were firstly dropped, while chlorines at ortho-position start to eliminate when other chlorines have been removed.

In comparison, in the conformation of PCN-75, shown in Fig. 6c, the two aromatic rings are in the same plane (Su et al., 2014). The dihedral angles of $0^{\circ}$ in PCN-75 lead to the existence of steric effect between chlorines at ortho-position. The PCN isomers that featured chlorine atoms at either set of positions i.e., 1 and 8, or 4 and 5 were determined as nonstable (Zhai and Wang, 2005; Su et al., 2014). Contrary to PCB-209, the steric repulsion of chlorines at ortho-position in PCN-75 results in their instability and been preferentially attacked from the top and bottom of the conjugated aromatic planes. Once one of chlorines in either set of ortho-position at 1 and 8 , or 4 and 5 removed, the steric repulsion could be weakened. In the thermal degradation of PCN-75 over $\mathrm{Fe}_{3} \mathrm{O}_{4}$, the first and second hydrodechlorination steps preferentially occurred respectively at 1- and 8-, or 4-, resulting in the successive formation of PCN-73 and 66/67 (Su et al., 2014). Once the steric repulsion at ortho-position was weakened, the dechlorination proceeded preferentially at flanked meta-position. The dechlorination of PCN-75 was controlled by thermodynamically stabilized products and promoted by steric effects (Su et al., 2014). The opposite roles of the steric effect in ortho-position between PCB-209 and PCN-75 might be due to the difference of the $\pi$-conjugated plane caused by the dihedral angle of $90^{\circ}$ and $0^{\circ}$ of the two aromatic rings.
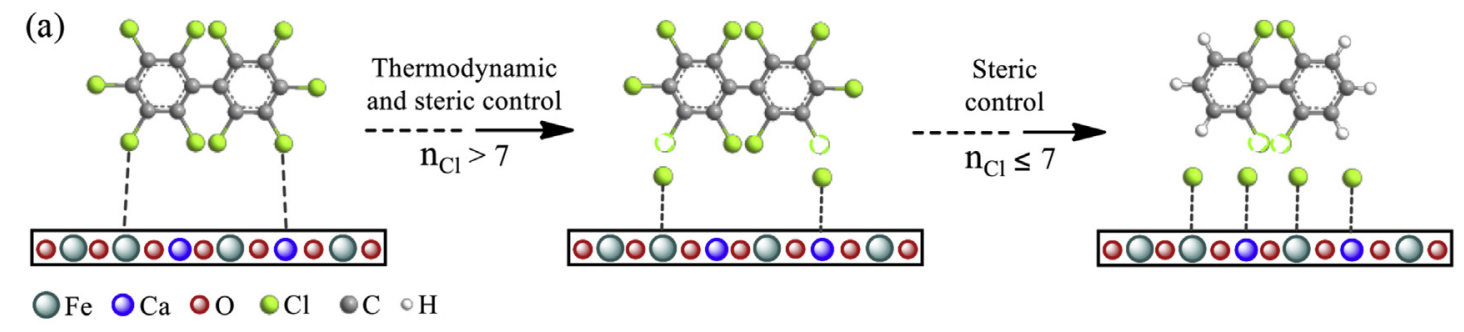

(b)

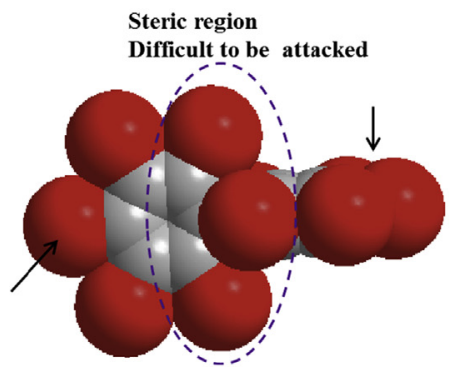

(c)

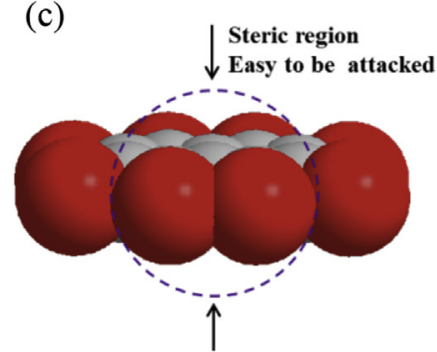

Fig. 6. Hydrodechlorination mechanism of PCB-209 over $1 \% \mathrm{Ca}-\mathrm{Fe}_{2} \mathrm{O}_{3}$ (a) and the optimized geometries of the minima states of (b) PCB-209 and (c) PCN-75. 


\section{Conclusion}

Ca species-doped $\mathrm{Fe}_{2} \mathrm{O}_{3}$ with different $\mathrm{Ca} / \mathrm{Fe}$ molar ratio was synthesized and characterized. The material activities decreased with the increasing $\mathrm{Ca}$ doping amount, in which $1 \% \mathrm{Ca}-\mathrm{Fe}_{2} \mathrm{O}_{3}$ exhibited the highest activity on PCB-209 degradation at $300{ }^{\circ} \mathrm{C}$ for 60 min with a reaction rate constant of $0.103 \mathrm{~min}^{-1}$ of pseudo-first order. PCB-209 proceeded hydrodechlorination pathway producing series of NoCB to MoCB products with the respective predominant isomers of PCB-207, PCB-197, PCB-176, PCB-184, PCB-150, PCB-136, PCB-148, PCB-104, PCB-96, PCB-54, PCB-19, PCB-4 and PCB-1. This indicated the dechlorination was more favored on meta- and parathan on ortho-positions. The dechlorination driving force was different with dechlorination steps. When PCB-209 was dechlorinated stepwise to OctaCBs, all four ortho-positions were substituted with chlorines because the dechlorination driving force was controlled by thermodynamic stabilities of products and the steric effects which prevented the hydrodechlorination at ortho-positions. When the formed OctaCBs were further dechlorinated to lower chlorinated biphenyls with the number of chlorines not more than 7 , the steric effect kept the predominant HeptaCB to MonoCB isomers with chlorines substituted at ortho-positions. In comparison, the chlorines at ortho-positions in structurally similar PCN-75 were preferentially attacked due to the steric effects. The opposite roles of the steric effect in ortho-position between PCB-209 and PCN-75 might be due to the difference of the $\pi$-conjugated plane which locates in the two separate conjugated systems in PCB-209 due to the existence of $\mathrm{C}-\mathrm{C}$ bridge bond, but locates in the same conjugated plane in PCN-75.

\section{Acknowledgments}

This study was supported by the National 973 Program (2015CB453103), Beijing Municipal Science and Technology Commission (Z141100001014001), the National 863 Program (2012AA062803), the Strategic Priority Research Program of the Chinese Academy of Sciences, (XDB14020102), and the National Natural Science Foundation of China (21377147, 21177141, 21321004).

\section{Appendix A. Supplementary data}

Supplementary data related to this article can be found at http: //dx.doi.org/10.1016/j.chemosphere.2015.08.022.

\section{References}

Abramowicz, D.A., 1990. Aerobic and anaerobic biodegradation of PCBs: a review. Crit. Rev. Biotechnol. 10, 241-251.

Addink, R., Olie, K., 1995. Mechanisms of formation and destruction of polychlorinated dibenzo-p-dioxins and dibenzofurans in heterogeneous systems. Environ. Sci. Technol. 29, 1425-1435.

Alonso, M. Casado, S., Miranda, C., Tarazona, J.V., Navas, J.M., Herradón, B., 2008 Decabromobiphenyl (PBB-209) activates the aryl hydrocarbon receptor while decachlorobiphenyl (PCB-209) is inactive: experimental evidence and computational rationalization of the different behavior of some halogenated biphenyls. Chem. Res. Toxicol. 21, 643-658.

Chen, M., Fan, L., Zheng, X., 2006. Effect of novel supporter on catalytic combustion of methane. J. Rare Earth 24, 447-450.

Decker, S.P., Klabunde, J.S., Khaleel, A., Klabunde, K.J., 2002. Catalyzed destructive adsorption of environmental toxins with nanocrystalline metal oxides. Fluoro-, chloro-, bromocarbons, sulfur, and organophosophorus compounds. Environ. Sci. Technol. 36, 762-768.

Dorofeeva, O.V., Moiseeva, N.F., Yungman, V.S., 2004. Thermodynamic properties of polychlorinated biphenyls in the gas phase. J. Phys. Chem. A 108, 8324-8332.

Fan, Y., Lu, X., Ni, Y., Zhang, H., Zhu, M., Li, Y., Chen, J., 2011. Catalytic destruction of chlorinated aromatic pollutants over mesoporous $\mathrm{Cu}_{\mathrm{x}} \mathrm{Mg}_{1-\mathrm{x}} \mathrm{Al}_{2} \mathrm{O}_{4}$ spinel oxides. Appl. Catal. B Environ. 101, 606-612.

Gouin, T., Mackay, D., Jones, K.C., Harner, T., Meijer, S.N., 2004. Evidence for the "grasshopper" effect and fractionation during long-range atmospheric transport of organic contaminants. Environ. Pollut. 128, 139-148.
Hooker, P.D., Klabunde, K.J., 1994. Destructive adsorption of carbon tetrachloride on iron (III) oxide. Environ. Sci. Technol. 28, 1243-1247.

Huang, L., Su, G., Zhang, A., Shi, Y., Xia, C., Lu, H., Li, L., Liu, S., Zheng, M., 2013. Degradation of polychlorinated biphenyls using mesoporous iron-based spinels. J. Hazard. Mater 261, 451-462.

Jia, M., Su, G., Zheng, M., Zhang, B., Lin, S., 2011. Development of self-assembled 3D $\mathrm{Fe}_{x} \mathrm{O}_{y}$ micro/nano materials for application in hexachlorobenzene degradation. J. Nanosci. Nanotechnol. 11, 2100-2106.

Jiang, Y., Decker, S., Mohs, C., Klabunde, K.J., 1998. Catalytic solid state reactions on the surface of nanoscale metal oxide particles. J. Catal. 180, 24-35.

Koper, O., Lagadic, I., Klabunde, K.J., 1997. Destructive adsorption of chlorinated hydrocarbons on ultrafine (nanoscale) particles of calcium oxide. 2. Chem. Mater 9, 838-848.

Larcher, D., Sudant, G., Patrice, R., Tarascon, J.M., 2003. Some insights on the use of polyols-based metal alkoxides powders as precursors for tailored metal-oxides particles. Chem. Mater 15, 3543-3551.

LaRoe, S.L., Fricker, A.D., Bedard, D.L., 2014. Dehalococcoides mccartyi strain JNA in pure culture extensively dechlorinates aroclor 1260 according to polychlorinated biphenyl (PCB) dechlorination process N. Environ. Sci. Technol. 48, 91879196.

Lee, C., Huffman, G.L., 1989. Innovative thermal destruction technologies. Environ. Prog. 8, 190-199.

Li, Y.-X., Li, H., Klabunde, K.J., 1994. Destructive adsorption of chlorinated benzenes on ultrafine (nanoscale) particles of magnesium oxide and calcium oxide. Environ. Sci. Technol. 28, 1248-1253.

Lin, S., Su, G., Zheng, M., Ji, D., Jia, M., Liu, Y., 2012. Synthesis of flowerlike $\mathrm{CO}_{3} \mathrm{O}_{4}-\mathrm{CeO}_{2}$ composite oxide and its application to catalytic degradation of 1,2,4-trichlorobenzene. Appl. Catal. B Environ. 123, 440447

Lin, S.J., Su, G.J., Zheng, M.H., Jia, M.K., Qi, C.S., Li, W., 2011. The degradation of 1,2,4-trichlorobenzene using synthesized $\mathrm{Co}_{3} \mathrm{O}_{4}$ and the hypothesized mechanism. J. Hazard. Mater 192, 1697-1704.

Lu, H., Khan, A., Smirniotis, P.G., 2008. Relationship between structural properties and $\mathrm{CO}_{2}$ capture performance of $\mathrm{CaO}$-based sorbents obtained from different organometallic precursors. Ind. Eng. Chem. Res. 47, 62166220.

Ma, X., Feng, X., Guo, J., Cao, H., Suo, X., Sun, H., Zheng, M., 2014. Catalytic oxidation of 1, 2-dichlorobenzene over Ca-doped $\mathrm{FeO}_{x}$ hollow microspheres. Appl. Catal. B Environ. 147, 666-676.

Ma, X., Zheng, M., Liu, W., Qian, Y., Zhang, B., Liu, W., 2005a. Dechlorination of hexachlorobenzene using ultrafine Ca-Fe composite oxides. J. Hazard. Mater 127, 156-162.

Ma, X., Zheng, M., Liu, W., Qian, Y., Zhao, X., Zhang, B., 2005b. Synergic effect of calcium oxide and iron (III) oxide on the dechlorination of hexachlorobenzene. Chemosphere 60, 796-801.

Ma, X.D., Sun, H.W., He, H., Zheng, M.H., 2007. Competitive reaction during decomposition of hexachlorobenzene over ultrafine Ca-Fe composite oxide catalyst. Catal. Lett. 119, 142-147.

Peng, F., Fu, X., Yu, H., Wang, H., 2007. Preparation of carbon nanotube-supported $\mathrm{Fe}_{2} \mathrm{O}_{3}$ catalysts and their catalytic activities for ethylbenzene dehydrogenation. New Carbon Mater 22, 213-217.

PCBs Elimination Network (PEN). http://chm.pops.int/Implementation/PCBs/ PCBsEliminationNetwork/tabid/438/Default.aspx.

Schoonenboom, M.H., Zoetemeijer, H.E., Olie, K., 1995. Dechlorination of octachlorodibenzo-p-dioxin and octachlorodibenzofuran on an alumina support. Appl. Catal. B Environ. 6, 11-20.

Su, G., Lu, H., Zhang, L., Zhang, A., Huang, L., Liu, S., Li, L., Zheng, M., 2014. Thermal degradation of octachloronaphthalene over as-prepared $\mathrm{Fe}_{3} \mathrm{O}_{4}$ micro/nanomaterial and its hypothesized mechanism. Environ. Sci. Technol. 48, 6899-6908.

Subbanna, P., Greene, H., Desai, F., 1988. Catalytic oxidation of polychlorinated biphenyls in a monolithic reactor system. Environ. Sci. Technol. 22, 557-561.

Takasuga, T., Senthilkumar, K., Matsumura, T., Shiozaki, K., Sakai, S., 2006. Isotope dilution analysis of polychlorinated biphenyls (PCBs) in transformer oil and global commercial PCB formulations by high resolution gas chromatography-high resolution mass spectrometry. Chemosphere 62, 469-484.

Tanaka, Y., Zhang, Q., Saito, F., Ikoma, T., Tero-Kubota, S., 2005. Dependence of mechanochemically induced decomposition of mono-chlorobiphenyl on the occurrence of radicals. Chemosphere 60, 939-943.

Tauster, S.J., Fung, S.C., Baker, R.T.K., Horsley, J.A., 1981. Strong interactions in supported-metal catalysts. Science 211, 1121-1125.

The PCBs elimination network: the information exchange platform created for the risk reduction of polychlorinated biphenyls (PCBs). http://chm.pops. int/Implementation/PCBs/PCBsEliminationNetwork/Relatedarticlesandlinks/ PCBsInfoexchangeplatform/tabid/3016/Default.aspx.

The 12 initial POPs under the Stockholm Convention.http://chm.pops.int/ TheConvention/ThePOPs/The12InitialPOPs/tabid/296/Default.aspx.

Wang, Z.-Y., Han, X.-Y., Zhai, Z.-C., Wang, L.-S., 2005. Study on the thermodynamic property and relative stability of a series of polychlorinated biphenyls by density functional theory. Acta Chim. Sin. 63, 964-972.

Wang, Z., Yang, M., Shen, G., Liu, H., Chen, Y., Wang, Q., 2014. Catalytic removal of benzene over $\mathrm{CeO}_{2}-\mathrm{MnO}_{\mathrm{x}}$ composite oxides with rod-like morphology supporting PdO. J. Nanopart. Res. 16, 1-12.

Wania, F., 2003. Assessing the potential of persistent organic chemicals for longrange transport and accumulation in polar regions. Environ. Sci. Technol. 37, 1344-1351. 
Weber, R., Nagai, K., Nishino, J., Shiraishi, H., Ishida, M., Takasuga, T., Konndo, K., Hiraoka, M., 2002. Effects of selected metal oxides on the dechlorination and destruction of PCDD and PCDF. Chemosphere 46, 1247-1253.

Wiegel, J., Wu, Q., 2000. Microbial reductive dehalogenation of polychlorinated biphenyls. Fems Microbiol. Ecol. 32, 1-15.

Zhai, Z.-C., Wang, Z.-Y., Chen, X.-H., Wang, L.-S., 2005. DFT calculation on 204 polychlorinated biphenyls: their thermodynamic function and implication of $\mathrm{Cl}$ substitute position. J. Mol. Struct. 714, 123-131.

Zhai, Z., Wang, Z., 2005. Computational study on the relative stability and formation distribution of 76 polychlorinated naphthalene by density functional theory. J. Mol. Struct. 724, 221-227.
Zhong, L.S., Hu, J.S., Liang, H.P., Cao, A.M., Song, W.G., Wan, L.J., 2006. Self-assembled 3D flowerlike iron oxide nanostructures and their application in water treatment. Adv. Mater 18, 2426-2431.

Zhou, Z., Qi, Y., Xie, M., Cheng, Z., Yuan, W., 2012. Synthesis of CaO-based sorbents through incorporation of alumina/aluminate and their $\mathrm{CO}_{2}$ capture performance. Chem. Eng. Sci. 74, 172-180.

Zhu, L., Zhang, H., Li, W., Liu, H., 2007. Investigation of zinc powder modified by ultrasonic impregnation of rare earth lanthanum. Appl. Surf. Sci. 253, 9443-9449.

Zou, X.J., Tian, Z.L., Wang, X.G., Tan, M.W., Ding, W.Z., Lu, X.G., 2015. Formation of magnesium silicate on surface of silica for steam reforming of liquefied petroleum gas. Catal. Commun. 68, 116-119. 